Fecha de recepción: abril 2021

Fecha de aprobación: mayo 2021

Fecha publicación: junio 2021

\section{Festina Lente. La ponderación del tiempo con relación a la producción de objetos}

Mercedes Buey Fernández ${ }^{(1)}$

Resumen: El mundo globalizado se caracteriza hoy por tener un ritmo vertiginoso que ha invadido, casi sin resistencia, todos los órdenes de la vida. Se aceleran las capacidades y habilidades productivas, y con eso se pierde dimensión del tiempo. El análisis actual acerca del diseño industrial y cómo el diseñador se acomoda en este mundo en transición tiene dos aristas. Por un lado, el análisis de los desafíos globales que enfrenta, y cómo el rol del diseñador se redefine y reubica en ese nuevo escenario. Y por el otro, qué pasa con la producción de objetos de ese cambio. En este contexto el diseño industrial tiene mucho para decir. La reflexión está puesta puntualmente sobre el vínculo entre los retos adaptativos que enfrenta el diseño industrial en la Argentina y su relación con los principios slow design y las identidades regionales mediante un cambio metodológico y proyectual en el diseño.

Palabras clave: diseño industrial - slow design - consumismo - crisis - cultura material producción cultural - producción de objetos -transición.

[Resúmenes en inglés y portugués en las páginas 134-135]

(1) Diseñadora Industrial (UP). Ha sido profesora de la Universidad de Palermo en el Área de Diseño de Objetos y Productos de la Facultad de Diseño y Comunicación entre 2012 y 2018. A lo largo de su trayectoria se desempeñó como diseñadora senior y semi senior en diferentes empresas. Desde 2012 es socia gerente, diseñadora y fundadora de Estudio De Raíz y Yerba Mate Mathienzo, fue docente evaluadora de Proyectos de Graduación; es especialista en Gestión de Diseño (UBA) y asistente externa en el área de estudios ergonómicos y capacitaciones de diferentes empresas.

\title{
Introducción
}

La abrumadora velocidad con la que se inician y concluyen los procesos, es causa principal del desafío que enfrenta hoy el diseño. En los últimos veinte años los diseñadores se han enfrentado a numerosos cuestionamientos sobre la disciplina, la naturaleza de la tarea y la apropiación de conocimientos. Con frecuencia, son considerados meros conformadores 
formales o estilistas, responsables de una economía de consumo desenfrenado. Sin embargo, los diseñadores han logrado imponer un nuevo enfoque antropocéntrico del consumo. Al hacerlo han sido directamente responsables de un catálogo de impactos ambientales y sociales adversos, y han ayudado a fomentar nuevos hábitos de consumo (Fuad-Luke, 2005).

A medida que las sociedades se enfrentan a las nuevas cuestiones de agenda política, económica y culturales -léase: cambio climático, contaminación, escasez de agua, recursos energéticos, pobreza, malestar social y problemas de salud-, surgen nuevos cuestionamientos de diseño y con ello un diagnóstico desalentador: el paradigma de diseño contemporáneo parecía estar mal equipado para enfrentar los temas apremiantes del nuevo esquema mundial (Fuad-Luke, 2005).

Como si eso no fuera suficiente, a todas las preocupaciones que ya significaba reorientar esfuerzos para transitar los cambios geopolíticos sin morir en el intento de sobrevivir a los nuevos modelos socioeconómicos, se suma ahora un nuevo desafío: el de la valoración y comprensión del tiempo.

La velocidad y la aceleración constante son producto de una ambigua construcción social a partir de la cual uno pretende controlar y organizar ciertos aspectos de la vida, y a la cual se ha asignado cada vez más atribuciones. Woodcock (1944) sostenía que "el reloj representa un elemento de tiranía mecánica en las vidas de los hombres modernos mucho más poderoso que cualquier explotador en tanto individuo o que cualquier otra máquina" (p. 1). Para él, es el hombre moderno el que por algún motivo vive regulado por el tiempo y le otorga, de manera consciente o inconsciente, un valor mayor al que tenía en la antigüedad. Según él, no se hallará sino unos pocos hombres que se hayan preocupado por el tiempo en términos de exactitud matemática, a diferencia de hoy, tiempo en el que el reloj dicta los movimientos e inhibe las acciones de la mayoría. "El reloj transforma el tiempo, que pasa de ser un proceso natural a una mercancía que puede ser medida, comprada y vendida como si de jabón o pasas se tratara" (Woodcock, 1944, p. 1).

Sin embargo, ¿qué sucede cuando el ritmo vertiginoso en el que la humanidad se ve envuelta comienza a no ser el deseado? ¿Son las pequeñas iniciativas la respuesta a los desafíos globales? ¿O es el diseño una víctima más de su propio éxito, al servicio de la industria, el consumismo y una agenda económica global politizada? (Fuad-Luke, 2005).

Ante este panorama desconcertante, y dado el creciente interés por el análisis de las manifestaciones del mundo en transición en el diseño industrial, el presente escrito intenta analizar el vínculo entre los retos adaptativos que enfrenta el diseño industrial en la Argentina, con la emergencia de identidades regionales, para relacionar estos con la huella slow design y los consecuentes cambios metodológicos y proyectuales en el diseño industrial hoy.

\section{Emergencia de Identidades Regionales}

Los signos del mundo en transición que se plantean no son fruto de una imaginación frondosa, han comenzado a suceder hace apenas diez años y están sucediendo ahora. 
La década del 90 dio lugar a un modelo económico de tipo excluyente que sentó las bases para la conformación de nuevas modalidades de integración, de reinserción a la estructura socio-productiva y de adaptación y supervivencia económica y social (Correa, 2008 y Kessler, Lvovich, 2003). No obstante, en contrapartida al período de decadencia económica y social que generó instancias de "pauperización y exclusión", el estallido generalizado del 2001 inició un período de nuevos modelos de integración y participación en la estructura social y mercado laboral. En relación a esto, Correa (2008) afirma que fueron esos los que dieron lugar a la configuración de nuevos actores principales, y en muchos casos, a la reinserción de los ya existentes, bajo nuevas modalidades de participación social y económica (p. 1).

Para muchos, la crisis económica de 2001 fue el desencadenante que los impulsó a lanzarse al mercado con nuevas propuestas de diseño. Desde entonces, los diseñadores han revisado su rol en el crecimiento económico nacional, y la Argentina ha asistido con gran aceptación a la iniciación de diseñadores locales y emergencia de microempresas de diseño, con el potencial suficiente para servir de manera innovadora a un país en crisis (Mon, 2013). Estos nuevos actores -sumado a aquellos reubicados- son los que irrumpieron en casi todas las escenas de la vida cotidiana y comienzan a dar cuenta de un fenómeno de crecimiento caracterizado por nuevos modos de participación en el mercado, una resignificación del campo cultural -a nivel productivo y de consumo- (Correa, 2008).

Entre los años 1983 y 2003 aproximadamente, se sucedieron en la Argentina ocho presidentes constitucionales, sólo cuatro fueron elegidos por el pueblo, y únicamente uno completó su mandato (Mayer, 2012, p. 21). La sensación de caos y vacío político, junto con el contexto de derrumbe de los discursos económicos, sociales y culturales dominantes, producto de la "fenomenal eclosión del paradigma neoliberal" (Mon, 2013) junto con las políticas de reforma económicas -ley de Convertibilidad-, que desembocó inevitablemente en la profunda crisis del 2001, fueron la patada inicial que impulsó nuevas estrategias de acción (Rojas, 2003, p. 123).

En ese contexto donde el saldo entre creación y supervivencia de empresas es claramente negativo, el desempleo se viraliza, las prácticas hasta entonces exitosas pierden legitimidad, sobre todo, se vio afectada la esencia básica de la vida social -confianza mutua y las reglas confiables de interacción social- (Rojas, 2003); los emprendedores empiezan a brotar como yuyos en el campo con ideas de supervivencia, sin más pretensión que la de generar sus propios ingresos, aferrándose a la autogestión laboral. De este modo, son incalculables la cantidad de emprendedores que lograron desarrollar habilidades y destrezas suficientes para proponer alternativas creativas en medio de un contexto altamente desalentador.

Aunque se carece de cifras exactas, muchos mantienen una postura coincidente y afirman que el emprendedurismo es un factor importante para el desarrollo económico y su importancia es decisiva para reparar pérdidas como las sufridas en 2001. Según informes del Global Entrepreneurship Monitor (GEM), en Argentina, al año 2013, la tasa de actividad emprendedora (TEA) fue de un 15,9\% (Perazo, 2016), signo de que los cambios en el ámbito productivo estarían compensando las pérdidas sufridas durante casi una década, marcando un período de recuperación económica y aumento en la confianza institucional (Gem, 2013). 
Esto quiere decir que, aunque en tiempos de crisis algunos lloran, otros prefieren vender pañuelos y deciden dejar de esperar el milagro que les evite el sacrificio y les regale el éxito, para fundar empresas que, impulsadas por la necesidad, desafíen los modos tradicionales de trabajo y cuestionen los modelos comerciales de diseño.

Son varios los estudios y diseñadores que, desde principios del siglo XXI hasta aquí, han iniciado un camino a contramano de los discursos de moda masiva, para producir bajo estándares diferenciados y, contrario a lo que muchos podían vaticinar, no sólo lograron despegarse de los discursos de moda y consolidarse económicamente, sino que, lograron la legitimización necesaria para poder ser considerados hoy referentes de diseño.

Sus comienzos informales y prácticas poco ortodoxas pronto aceleraron los cambios estructurales en la economía. Fueron ambiciosos y estimulantes. Ingresaron en el juego destacándose como nueva competencia, elevando así la vara de la competitividad laboral, intelectual y productiva, y contribuyendo al rescate de la industria masiva, que se nutrió de sus procesos diferenciales y discursos marginales. Su realidad desfavorable se convirtió en sinónimo de crecimiento y el lugar marginal donde debieron ubicarse, devino luego en la ubicación deseada para rechazar los límites que atentaban contra su libertad creativa. De este modo, el escenario se complejizó y comenzaron a convivir los discursos de moda y grandes marcas, con las propuestas de pequeños autores y se volvió cada vez más importante superar, como expresa Saulquin (2011) "el tradicional dilema que se planteaba entre las tendencias representadas en producciones seriadas digitadas por grupos guiados sólo por las demandas del mercado, y las producciones del diseño de autor que hasta hace pocos años solo se podían industrializar en pequeñas series" (p. 35).

En tiempos de crisis las grandes fábricas comienzan a achicarse y los proveedores comienzan a necesitar de pequeños clientes para sobrevivir. En este punto, los emprendedores depositan menos ilusión en genialidades aisladas y en cambio dedican más tiempo a la detección de oportunidades. No sólo innovan discursivamente a través de sus productos, sino que, introducen cambios en los métodos productivos de esos objetos. Casi como conformando hubs de pensamiento, los nuevos empresarios del diseño proponen nuevos esquemas colaborativos y desafían cualquier lógica proyectual y estética tradicional reinante. Proponen nuevos materiales y procesos constructivos. Pero, lo que verdaderamente plantean es un cambio en la concepción de las ideas y objetos.

Saulquin señala que un sistema productivo basado en la aceleración de los consumos y el consumismo no es sostenible ambientalmente. Por lo tanto, el sistema productivo está obligado a cambiar por supervivencia, no únicamente por ser "buenos y éticos" (Saulquin, 2018). La necesidad por encontrar nuevos horizontes creativos en un contexto de limitantes productivas es que empieza a apartar a los diseñadores de los parámetros ortodoxos del diseño y los acerca cada vez más a la innovación genuina (Mon, 2013). La supervivencia de la sociedad es la que exige que los parámetros cambien, y el prestigio empieza a estar ligado con cuidar lo medio ambiental y las personas (Saulquin, 2018).

Los cambios no son cosméticos, son culturales. La gente encuentra en este tipo de diseño sus maneras de protestar, presionar a la industria, desafiar a la crisis y sus líderes. Se juzgan decisiones por el proceso más que por el resultado. Las ganas de transformar el presente para apostar al futuro son cada vez más fuertes. Un new normal comienza a vislumbrarse y con él las huellas de nuevas metodologías y concepciones de diseño. El diseño de objetos 
busca la sustentabilidad en contraposición de la rapidez de la producción para su comercialización.

En esta sociedad, Hauffe afirma que "la auto-presentación y el diseño experiencial quizás estén comenzando a encontrar una voz en la cultura del diseño, aunque en contra de la cultura corporativa dominante dentro del diseño" (1998, en Fuad-Luke, 2004, p. 3).

\section{Respuestas lentas}

Con el nuevo objetivo de dirigirse hacia experiencias más enriquecedoras, los diseñadores actuales buscan ser intérpretes de los cambios que se están gestando y no simplemente traductores. Los diseñadores se muestran cada vez más inconformistas y apasionados. Y en este sentido, pensar a largo plazo es la premisa moderna. Entendiendo que se va a pasar lo que queda de la vida en el futuro, es que ese futuro se debe diseñar hoy. Si la industria no se siente presionada, entonces nada va a cambiar en la ésta y si nada cambia, probablemente en unos años ya no se tenga más planeta (Polar, 2014).

A nivel generalizado, existe un sentimiento cada vez más fuerte que condena a la indolencia frente a los problemas ambientales y sociales que amenazan al planeta. La humanidad vuelca hacia una conciencia colectiva que se refleja en los objetos de diseño. Esto ha alimentado el debate acerca de nuevas miradas que acaban por convencer a todos de la responsabilidad social y ecológica del diseño.

Si la supervivencia humana depende de una atención urgente a los temas medioambientales, (Papanek, 1995) la cuestión entonces es pensar ¿cómo responderá el diseño a los desafíos contemporáneos de los millones de personas que habitan el planeta? ¿Encontrarán los diseñadores más y mejores formas de concebir productos para vivir de manera más sostenible? ¿Se puede a través del diseño crear nuevas percepciones y valores de tiempo que contribuyan a desacelerar el impacto de la globalización y su consiguiente degradación ambiental y sociocultural? Estos son algunos de los interrogantes que regala la poscrisis. En 1995 comienza a oírse en Italia un nuevo grito de independencia humana. Una expresión de descontento y una reacción contra la cultura de la rapidez que ayudaría a todos avanzar hacia un futuro más sostenible. Este movimiento comienza puntualmente como un movimiento antagónico, de resistencia al fast food, con el objetivo de desacelerar el metabolismo humano y reivindicar la buena mesa. Pronto esta reivindicación deviene en una corriente cultural y tiñe a todos los órdenes de la vida: como la salud, el trabajo, la educación, el tiempo libre, etc. En 1999, se amplía la filosofía del slow food (Petrini, 1995 2003) con el nacimiento del Cittaslow (ciudad lenta) (Cittaslow, 1999), que deben resistir a la homogeneización y la expansión de los suburbios (Boullosa, 2008).

Inspirado por estos movimientos italianos, Alastair Faud-Luke concibe en 2002 el movimiento slow design, como una forma de centrar el diseño en el bienestar de las personas y el medio ambiente. Supone también un nuevo paradigma de diseño que conlleve a un cambio de comportamiento tal, que signifique una forma única y vital de activismo creativo, con nuevos valores para el diseño y una colaboración hacia un cambio en torno a la sustentabilidad (Fuad-Luke y Strauss, 2008). 
Esta nueva corriente de diseño es considerada una nueva herramienta de evaluación para fomentar las prácticas sociales, culturales y medioambientales de diseño. Sus principios ofrecen la oportunidad de encontrar cualidades nuevas en las diferentes etapas de investigación, ideación y producción de objetos, permitiendo interrogar ideas y procesos, y evaluar resultados tangibles y comprendiendo mejor los posibles impactos futuros (Strauss et al, 2003).

El slow design va mucho más allá del acto de diseñar. Es un enfoque holístico, lento, considerado y reflexivo. Es considerado como una forma de centrar el diseño en el bienestar de las personas, con el objetivo de alcanzar un bienestar positivo para la sociedad (FuadLuke, 2008). El autor propone tomar control del tiempo, más que someterse a su tiranía, destacando los beneficios de hacer las cosas más despacio, dedicándole tiempo suficiente a la primera fase, logrando acortar tiempos en la segunda. Tampoco se trata de obligar a las personas a bajar el nivel de su producción, ni hacerlas más lento, sino con calma y detenimiento. Apunta a dar soporte, a hacer las cosas en el momento adecuado, comprendiendo y reflexionando al hacerlas (Honoré, 2004). Es también un modo de apostar a la valentía y aprovechar las oportunidades.

Los principios del slow design han sido pronto adoptados por todos los consumidores éticos y validados por los medios de comunicación. Periodistas de renombre como Carl Honoré afirman que el mensaje tiene eco en todos los grupos demográficos por igual. Esto subraya la fuerza de aquél -sostiene Honoré- y es la prueba de que no estamos ante una cosa de moda que lees un artículo en el suplemento del domingo y ya no existe más dentro de un mes (Honoré, 2005). Para el periodista lo que está sucediendo no es moda de ejecutivos estresados o de clases acomodadas, sino que es un cambio histórico que se da después de un siglo de aceleración constante y que no entiende de fronteras ni diferencias sociales y económicas.

Demuestra que "el virus del apuro está en todos lados y que el momento de cambio ha llegado". Es el mismo Honoré, quien explica en sus textos y comunicaciones, que lo que denuncia no es la rapidez en sí misma, sino el hecho de que se vive siempre corriendo por el carril rápido y se ha creado una cultura de la prisa donde se busca hacer cada vez más cosas con cada vez menos tiempo y, donde la falta de paciencia, la hiperestimulación, la superficialidad y la multitarea, han generado una especie de dictadura social que poco espacio deja para la pausa, el silencio y todas las cosas que parecen poco productivas (Honoré, 2005). En resumen "un mundo tan impaciente y tan frenético que hasta la lentitud la queremos en el acto” (Honoré, 2004).

Decrecer el ritmo de vida para no degradarse, y demostrar falsa la creencia de que haciendo menos la vida se reduce. Porque, muy por el contrario, como sostienen todos aquellos en favor del nuevo ritmo slow, incluido el mismo Honoré, "al no estar atrapado en la telaraña de compromisos las cosas empiezan a ocurrir casi de forma sorprendente e inesperada" (Honoré, 2005).

La base del diseño lento es la sustentabilidad y su medio de distribución el comercio justo, que valore al productor y cuente su historia. Como primera medida, prescinde de la producción industrial indiscriminada en grandes series, más no de la innovación social. Es por esto que, el término no atañe únicamente a productos físicos, sino que, se refiere a pro- 
cesos creativos, producciones intelectuales y estilos de vida también. Por ende, se focaliza principalmente en creencias, en lo humanístico y en lo socio ambiental (Montaña, 2018).

\section{La producción del cambio}

Luego de la crisis de 2001, se comenzó a ver en la Argentina una nueva forma de producir y concebir los productos. La necesidad de adaptar los procesos al cambio cultural, económico y ambiental, y a las nuevas demandas de los consumidores, marcaría en rumbos de diseño en los próximos años. Junto con esto se inició una era de indefiniciones, de volatilidad en las formas actuales de diseño y producción, y una falta de sistematización y coherencia que vuelven difícil la tarea de establecer parámetros sistemas teóricos o la preponderancia de una corriente de pensamiento sobre otra.

Los diseñadores argentinos probablemente no eran conscientes de esto, y los nuevos modos de integración y participación social que dieron lugar a la configuración de nuevos actores y escenarios económicos, fueron en realidad una respuesta natural e impulsiva de mera supervivencia económica. Lo cierto es que, por un motivo u otro, las producciones de los nuevos jóvenes independientes se definen a partir de ese momento como nuevos espacios de participación económica y cultural, y son presentados como objetos simbólicos de valor distintivo, que aportan identidad al usuario y caracterizados por la elección de materias primas locales o recicladas, el aprovechamiento de saberes productivos locales y el uso de formas (Correa, 2008, p. 3). El auge por lo no-masivo encuentra sus orígenes en la década de los 90 junto con la definición de nuevos perfiles de consumidores que se definió más arriba, y que comenzaron a manifestarse en favor de nuevas concepciones del tiempo y formas de vivir (Correa, 2008).

Esta generación actúa a corto y mediano plazo, pero siempre pensando a largo plazo. En este sentido, hablar de sus objetos es hablar de ellos, de la sociedad en la que están inmersos y de las relaciones culturales del diseño y los objetos que conciben (Bonsiepe, 1969, p. 102). En mayor o menor medida las preocupaciones y anhelos de los diseñadores en cuestión están reflejados en los objetos diseñados y, por tanto, no se trata de las nuevas formas en sí, sino de, las nuevas formas como expresiones cambio y calidad mejorada en un contexto de cambio permanente (Sol, 1988, p. 127). En definitiva, como dice Bonsiepe (1969), "la calidad de estos objetos, o la falta de ella, permite conclusiones sobre una sociedad y una cultura" (p. 102). En relación a ello, la buena práctica sería entonces la de construir una teoría en base a hechos empíricos. Lo ideal no sería hacer un análisis sobre la mera enunciación de ideas e intenciones, sino, direccionar la mirada a los hechos concretos.

Los objetivos de esto son difíciles, pero no utópicos. Los principios rectores que regulan la producción poscrisis son los de la oportunidad y la apuesta, la resiliencia, la adaptabilidad y la responsabilidad social. Tal como expresa Maldonado (1966), "lo importante no es encontrar una definición abstracta -o literaria-, sino operativa (...) adecuada a las exigencias de lo real", que pueda ayudar a guiar con éxito la acción, y a su vez, indicar también los métodos para alcanzarlos (p. 82). 
Probando falso aquello que Papanek dijo alguna vez acerca de que hay profesiones más dañinas que el diseño industrial, pero son muy pocas (p. 14), Thackara (2006) está convencido de que actualmente se están diseñando nuevos sistemas y servicios que ayudan a repensar el diseño como un factor de cambio cultural, siendo sustancialmente menos nocivos para el medio ambiente, y socialmente más responsables. Según él, ahora se observan las cosas con más atención y se integran con una conciencia ambiental mucho mayor. Los diseñadores actuales están evolucionando de su condición de creadores individuales de objetos, a la innovadora tarea de facilitar cambios entre grandes grupos de personas. Y, quizás porque para escapar de la crisis hacen más falta el ingenio y la creatividad que el dinero, es que la "sensibilidad al contexto, a las relaciones y a las consecuencias, son aspectos clave de la transición del desarrollo inconsciente al diseño responsable" (p. 49).

En este contexto, los diseñadores actuales son señalados como agentes de desarrollo sustentable indiscutibles. Sus creaciones son reconocidas como el fiel reflejo de la cultura donde son concebidos, y se las reconoce como una forma de expresión cultural. Su influencia es tan fuerte, que rápidamente tiñe a otros en la cadena, aportando valor e impulsando a trabajar de manera más sustentable y sostenible desde los comienzos de cualquier proyecto -sea de diseño o no-, defendiendo no sólo el cambio cultural, sino, incentivando la creación de nuevos modelos económicos. Por ejemplo, el caso de las economías circulares. Incluso, podría compararse con el concepto de "de la cuna a la cuna" acuñado en 2002 por Braugnart y McDonough.

Actualmente, el desafío de proponer estrategias que aporten beneficios económicos a las empresas hace que éstas se valgan sí o sí, de la innovación como recurso clave para aprovechar las oportunidades que el cambio cultural brinda, impulsando por ejemplo experimentaciones con materiales naturales -como en la bio-fabricación-, virando así a modos mucho más sustentables en toda la cadena productiva.

Existen muchos ejemplos de productos fabricados bajo este concepto, objetos que al finalizar su vida útil pueden desmontarse y separarse en unidades biodegradables y reciclables; pero quizás lo más interesante sea exponer los casos de objetos concebidos con esta filosofía desde el momento cero.

Es el caso de las carpas de campaña KarTent (Portheine y Kommer). Estas son carpas de campaña fabricadas a partir de cartón de embalaje, y apuntadas especialmente al uso en recitales, por ejemplo. Año tras año se utilizan unas 25 mil carpas de nylon en diferentes eventos musicales, pero la mayoría de ellas luego queda descartada en el mismo lugar, en zanjas, ríos, y en el mejor de los casos, la basura. Por eso, las KarTent, fueron diseñadas para ser utilizadas por hasta dos personas y luego descomponerse o reciclarse. Lo clave no está en el material o la carpa, lo clave radica en el concepto de uso y descarte en determinado contexto.

En el mismo sentido, aunque desde un punto de vista más conceptual, otros desarrollaron un dispositivo ralentizador de mensajes de texto. El aparato -Slow Messenger- no busca ser una solución práctica de comunicación, sino que, pone en valor la importancia del tiempo a través de la experiencia de esperar. La Eco-Cathedral de Lois le Roy, es otro ejemplo declarativo del movimiento lento.

Dentro del lineamiento conceptual y experiencial, pero de manera más concreta, reconocible y aplicable en lo inmediato, los espacios peatonales, la ampliación de espacios verdes 
o ensanchamiento de veredas, las piezas de mobiliario urbano presente en varios parques por ejemplo, son conceptos que se vinculan perfectamente con el diseño lento.

El Banco Villanueva en Colombia, está íntegramente realizado en concreto. El concreto lo vuelve casi indestructible, la morfología se inspira en los atributos de la ciudad, la imagen es atemporal y entiende la cultura del lugar -cuenta con un espacio para atar bicicletas-. Todas estas características definen al objeto como uno de diseño lento.

Desde el ámbito de la construcción, Park 20 | 20 en Haarlemmermeer, cerca de Ámsterdam, es otro ejemplo concreto de esto. Los edificios dentro de este parque empresarial de los Países Bajos están diseñados para ser fáciles de desmontar. Al remover un edificio, algunas partes pueden regresar al suelo donde sirven como nutrientes biológicos. Otras partes son reutilizadas como materiales para nuevos productos o edificios. Muchos techos tienen paneles solares, por lo que la energía solar se puede utilizar para las necesidades energéticas. En este entorno, la inspiración se promueve mediante encuentros profesionales y creativos, centrados en la salud y el bienestar natural de los usuarios (Park, 2020 s/f). Por su parte, Desso una empresa de alfombras que desde el año 2008 entendió que "la sostenibilidad era una forma de ahorrar costes" (Daelmans, 2012), utiliza hilo de nylon regenerado Econyl, incluidos los desechos de la planta, para hacer un negocio sin residuos. El trabajo con bioplásticos es otro ejemplo concreto de aplicación inmediata de una nueva forma de concebir productos. No solo por el reemplazo de materiales altamente contaminantes por aquellos derivados de productos vegetales (como la fécula de maíz o soja) sino, por la especial atención a todas las etapas del producto (producción, uso y descarte). Existen desde bolsas biodegradables hasta botas de esquí generadas a partir del algodón y el bambú (Botas Renu, marca Atomic).

En un análisis amplio de la temática, la bio-fabricación como concepto puede significar el comienzo de una nueva industria escalable y sostenible. La misma puede constituir la puerta de entrada a una industria totalmente sustentable, donde cada diseñador entiende que sus decisiones particulares tienen impacto global. Donde ya no se necesite dañar animales para obtener cuero, porque el mismo se puede obtener a partir de la síntesis y cultivo de células aisladas que se extraen sin vulnerarlos. O donde se pueda reemplazar el telgopor (tela gomosa porosa) por el aglomerado a partir del crecimiento de organismos fúngicos y descarte de yerba mate, como hace el diseñador Silvio Tinello.

La marca argentina de anteojos Qualia es otro ejemplo de empresa argentina nacida con el objetivo de ser solución activa frente a un problema de todos, fabricando sus anteojos únicamente con plástico recuperado de descartes industriales.

Estos son sólo algunos de los ejemplos que vienen a sintetizar el cambio cultural que se está viviendo y que, tarde o temprano, termina por modificar los modos actuales de diseñar y vivir. Si bien estos cambios culturales llevan tiempo, también suelen ser más efectivos.

\section{Beneficiar la salud de la tierra}

La figura del diseñador, desde sus inicios, se ha ido configurando en torno a las demandas y requerimientos del mercado, proyectando todo tipo de bienes para satisfacer necesida- 
des sociales, volviéndolo ciertamente vulnerable a los contextos económicos y productivos imperantes. Esta vulnerabilidad inherente a la figura del diseñador, cuya labor se encuentra altamente imbricada con los procesos productivos, y mismo con los propios vaivenes de mercado.

La figura del diseñador, desde sus inicios, se ha ido configurando en torno a las demandas y requerimientos del mercado, proyectando todo tipo de bienes para satisfacer necesidades sociales, volviéndolo ciertamente vulnerable a los contextos económicos y productivos imperantes. Esta vulnerabilidad inherente a la figura del diseñador, cuya labor se encuentra altamente imbricada con los procesos productivos, y mismo con los propios vaivenes de mercado.

Desde sus inicios, la profesión del diseñador industrial ha estado supeditada a la mirada crítica de los estudios sobre la cultura material. Alimentada por la necesidad de diferenciación, las posibilidades de venta, y la demanda constante producción y cambio o muerte, la figura del diseñador se ha ido moldeando de acuerdo a los requerimientos y demandas de los mercados imperantes. Se ha visto, sin embargo, como esta peculiaridad casi inherente a la profesión y vista de primera medida como característica de gran adaptación y supervivencia, es la misma que la vuelve, en la misma medida, vulnerable a los diferentes contextos.

La locura consumista actual, sumada a los contextos antes señalados demandan un pensamiento futuro, desde el hoy. Los diversos cambios sociales, culturales, económicos y tecnológicos marcaron un cambio en la forma de entender la cultura y de consumirla. Pensar hacia adelante es imperioso si se quiere zanjar la brecha de las dicotomías actuales, donde países del primer mundo gastan más dinero en cosméticos que lo que gastan países pobres en salud (Bengoa, 2018).

La contrapartida de esto ha sido el tránsito de modelos productivos impersonales, y con altos niveles de obsolescencia, hacia otros que reivindiquen la periferia, pensando al diseño desde el margen, pero, logrando mantenerse en el centro de la acción. Invitan a re ponderar el empleo del tiempo, con el objetivo de evitar caer en la trampa de la producción por la producción misma y el apuro como característica valorable.

Reflexionar y darse el tiempo para conocer las limitaciones es lo que hace entender a los diseñadores sus posibilidades y responsabilidades, por encima de sus habilidades como herramienta de producción.

La producción de estos tiempos de cambio puede parecer contradictoria, pero allí mismo, es donde radica su belleza. Las obras no son funcionales a ningún contexto económico o sociedad consumista, superficial e inmediato. Las piezas son el soporte expresivo de ideas que generan polémica y encienden debates. Son declaraciones.

El objetivo hoy es beneficiar la salud de la tierra.

\section{Bibliografía}

Bengoa, G. (2018). El diseño industrial y la proliferación de teorías. Recuperado el 20/11/2018. Disponible en: https://maestriadicom.org/articulos/el-diseno-industrial-y-la-prolifera cion-de-teorias/ 
Boullosa, N. (2008) Buscando el "tempo" del Slow Design. Recuperado el 3/9/18. Disponible en: https://faircompanies.com/articles/buscando-el-tempo-del-slow-design/

Braungart M. y McDonough W. (2005). De la cuna a la cuna: rediseñando la forma en que hacemos las cosas. Mdrid: McGraw-Hill.

Correa, M. (2008). El diseño como nueva cultura identitaria: aproximación al análisis de los jóvenes diseñadores independientes de la ciudad de Buenos Aires. Jornadas de Cuerpo y Cultura de la UNLP, 15 al 17 de mayo de 2008, La Plata, Argentina. Recuperada el: 8/9/18. Disponible: en: http://www.memoria.fahce.unlp.edu.ar/trab_eventos/ev.671/ev.671.pdf

Daelmans, R. (2012). Desso utiliza el principio cradle to cradle en la fabricación de moeuqetas. Recuperado el 5/9/18. Disponible en: https://ec.europa.eu/environment/ecoap/ about-eco-innovation/experts-interviews/20121001_es

Fuad-Luke, A (2002). 'Slow Design': A paradigm shift in design philosophy?, Development by Design, Bangalore, India, 01-02 December 2002, accessed 17 Jan 2008.

Fuad-Luke, A (2008). 'Slow Design', pp361-363 in Ehrloff and Marshall eds., Design Dictionary: Perspectives on Design Terminology, Birkhäuser, Basel, 2008.

Fuad-Luke, A. (2005). 'Slow Theory; A paradigm for living sustainably?'

GEM (2013). Global Entrepreneurship Monitor. 2013 Global Report. Recuperado el 2/9/18. Disponible en: http://www.cise.es/wp-content/uploads/GEM-2013-Global-Report.pdf Hauffe, T. (1998). Design - a concise history, Lawrence King, 1998.

Honoré, C. (2004) In praise of Slow, Orion, London, 2004.

Honoré, C. (2005). Hemos perdido la capacidad de esperar. Recuperado el 2/9/18. Disponible en: http://www.xtec.cat/ fserra22/docs/arts/honore-lentitud.pdf

Mon, L. (2013). Diseño en Argentina: Hacia la construcción de nuevos paradigmas. Cuadernos del Centro de Estudios en Diseño y Comunicación. Ensayos, (44), 83-99. Recuperado en 31 de Agosto de 2018, Disponible en: http://www.scielo.org.ar/scielo.php?script=sci_arttext \&pid=S1853-35232013000200007\&lng=es\&tlng=es.

Montaña, J. (2018). La hora del diseño lento o "slow design". Latin American Contemporary Design. Recuperado el 2/9/18. Disponible en: https://foroalfa.org/articulos/que-es-eldiseno-lento-o-slow-design

Papanek, V. (1973). Design for the Real World. Londres: Bantam Books.

Park 2020. (s/f) Recuperado el 5/9/18. Disponible en: http://www.park2020.com/

Perazo, C. (2016). A contramano: los que se animan a emprender en tiempos de crisis. Recuperado el 2/9/18. Disponible en: https://www.lanacion.com.ar/1940807-a-contramanolos-que-se-animan-a-emprender-en-tiempos-de-crisis)

Polar, H. (2014) La publicidad no necesita más egos. Recuperado el 31/8/2018. Disponible en: http://www.adlatina.com/publicidad/humberto-polar-\%E2\%80\%9Cla-publicidad -no-necesita-m\%C3\%A1s-egos $\%$ E2\%80\%9D

Redondo, 2015. https://wildwildweb.es/es/blog/slow-design-principales-caracteristicas

Rojas, M. (2003). Historia de Argentina. Edición en español. Buenos Aires: Timbro/SFN y Fundación CADAL.

Saulquin, S. (2011). Los desafíos en la formación de los diseñadores de indumentaria y textil, en Estudio Diseño de Indumentaria de Autor en Argentina 2011. Observatorio de Tendencias. INTI - Fundación Pro Tejer: Ediciones INTI. 
Saulquin, S. (2018) Susana Saulquin, la gran socióloga argentina de la moda, mano a mano con Infobae: "Hombres y mujeres ya no se vestirán con el cliché de lo femenino o lo masculino". Recuperado el: 20/8/18. Disponible en: https://www.infobae.com/tendencias/2018/07/06/susana-saulquin-la-gran-sociologa-argentina-de-la-moda-mano -a-mano-con-infobae-hombres-y-mujeres-ya-no-se-vestiran-con-el-cliche-de-lo-fe menino-o-lo-masculino/

Strauss, C. and Fuad-Luke, A. (2008) 'The Slow Design Principles - A New Interrogative and Reflexive Tool for Design Research and Practice. Recuperado el: 2/9/18 Disponible en: http://raaf.org/pdfs/Slow_Design_Principles.pdf

Thackara, J. (2006). In the bubble. Designing in a complex world. Londres: The MIT Press. Woodcock, G. (1944). La tiranía del reloj. War Commentary - For Anarchism, marzo de 1944. Recuperado el 2/9/18. Disponible en: http://uni-lliure.ourproject.org/wp-content/ uploads/2012/07/george-woodcock-la-tiran\%C3\%ADa-del-reloj.pdf

\begin{abstract}
Globalization is characterized by a dizzying pace that accelerates, almost without any resistance, all aspects of life. Productivity and innovation have been accelerated to a point, at which any dimension of time is lost.

How, industrial design, and specifically the industrial designer fits itself, and its abilities, into this constantly changing world calls for a double assessment. Firstly assessing the global challenges industrial design, as a whole, faces, and how the role of the designer is redefined in this new scenario. Secondly, what happens with the production of objects resulting of that change.

In this ever-changing context that globalization puts as in, industrial design has a lot to say. The paper analyzes, through methodological and creative action tools the link between the adaptive challenges faced by industrial design in Argentina and how they are related its with the principles of slow design and regional identities.
\end{abstract}

Keywords: industrial design - slow design - consumerism - material culture - cultural production - object production - transition.

Resumo: O mundo globalizado hoje se caracteriza por um ritmo vertiginoso que invadiu, quase sem resistência, todas as ordens de vida. As capacidades e habilidades produtivas são aceleradas e, com isso, a dimensão do tempo é perdida. A análise atual do design industrial e como o designer se acomoda neste mundo em transição tem duas arestas. Por um lado, a análise dos desafios globais que enfrenta e como o papel do designer é redefinido e realocado neste novo cenário. E por outro, que tal a produção de objetos dessa mudança. Nesse contexto, o design industrial tem muito a dizer. A reflexão é especificamente sobre o vínculo entre os desafios adaptativos que o design industrial na Argentina enfrenta e sua relação com os princípios do design lento e as identidades regionais através de uma mudança metodológica e de projeto no design. 
Palavras chave: desenho industrial - desenho lento - consumismo - crise - cultura material - produção cultural - produção de objetos - transição.

[Las traducciones de los abstracts fueron supervisadas por el autor de cada artículo] 